\title{
Evolution of Volatile Flavour Compounds during Fermentation of African Oil Bean (Pentaclethra macrophylla Benth) Seeds for "Ugba" Production
}

\author{
C. O. Nwokeleme and J. Obeta Ugwuanyi \\ Department of Microbiology, University of Nigeria, Nsukka 410001, Nigeria \\ Correspondence should be addressed to J. Obeta Ugwuanyi; jerry.ugwuanyi@unn.edu.ng
}

Received 16 July 2014; Revised 29 October 2014; Accepted 24 December 2014

Academic Editor: Sadhana Ravishankar

Copyright (C) 2015 C. O. Nwokeleme and J. O. Ugwuanyi. This is an open access article distributed under the Creative Commons Attribution License, which permits unrestricted use, distribution, and reproduction in any medium, provided the original work is properly cited.

\begin{abstract}
Fermented African oil bean (Pentaclethra macrophylla Benth) seed is a successful and well studied seasoning and snack in parts of Western Africa. GC-MS analysis of fermenting seeds revealed a mixture of several volatile aroma compounds which changed with time and starter organism. During natural mixed culture process 36 volatile compounds including 12 hydrocarbons, 10 esters, 5 alcohols, 2 phenols, 2 ketones, and one each of furan, amine, acid, thiophene, and lactone were identified. When Bacillus subtilis was used in pure culture, 30 compounds comprising 10 hydrocarbons, 8 esters, 3 alcohols, 2 amines, 2 sulfur compounds, and one of each of acid, aldehyde, phenol, ketone, and furan were identified. Sample fermented with B. megaterium produced 29 aroma compounds comprising 9 hydrocarbons, 10 esters, 2 nitrogenous compounds, 2 ketones, 3 alcohols, and one of each of lactone, aldehyde, furan, and amine. Methyl esters of various long chain fatty acids may be key aroma compounds, based on consistency and persistence. Qualitative or quantitative contribution of individual compounds may only be determined following flavour threshold analysis.
\end{abstract}

\section{Introduction}

African oil bean (Pentaclethra macrophylla Benth) is a member of the family Leguminosae. It is popular in Nigeria where it is known by several names such as Apara in Yoruba, Ukana in Efik, and, the most prominent, Ugba/Ukpaka in Igbo. Ugba is a popular Igbo condiment and delicacy made from traditional household solid state fermentation of African oil bean seeds. The fermentation is a mixed culture alkaline process involving a variety of microorganisms [1,2]. Although a variety of microorganisms are involved in the process, only the Bacillus spp. appear to be necessary for the development of typical flavour [2-6].

The methods of production and also the length of fermentation vary from one producer to another and with the final intended use resulting in nonuniform products. However, the basic method involves boiling the seeds for up to 12 hours, removing and slicing the cotyledons, soaking/washing the sliced cotyledons in several changes of water, and wrapping the sliced cotyledons for the fermentation to take place [1].
Beans that have been fermented for 2-3 days are taken as a snack delicacy directly or following seasoning and some further processing. Well fermented beans (up to 5 or more days) are added to soup as flavouring. Prepared in different ways, Ugba is an essential food item for various traditional ceremonies, and in instances it may be used as meat substitute in certain soups/gravies particularly for the rural poor [1].

Flavour is considered the quality index of Ugba [7] and plays an important role in consumer acceptability. Although fermented African oil bean seeds have typical flavour and appealing organoleptic quality, differences in flavour range and intensities exist. These vary perhaps as attributes of producer organisms and are due to the various volatile compounds produced by the fermenting population [8]. A great deal of work has been implemented in the microbiological characterisation of the fermentation process. However, unlike Asian and Pacific fermented seasoning, no work has yet been reported, to our knowledge, on the flavour components of Ugba and their evolution during the fermentation process. In fact, this knowledge gap is not restricted to Ugba but appears 
to cut across the entire gamut of African fermented foods, particularly of the genre of seasoning agents.

Knowledge of the volatile and flavour characteristics of the fermented oil bean seeds and their evolution will aid in the quality control of the process, modification of the flavour, and eventual synthesis of the Ugba flavour products for possible use in the seasoning of various factory processed and even home foods. This is important in view of declining production of seeds, due to deforestation, and the need to extend use of the appealing aroma of Ugba to other food types. The aim of this study was to identify the volatile flavour components of African oil bean seeds during natural and pure culture fermentation and to relate these to the fermentation progress.

\section{Materials and Method}

2.1. Traditional Production of Ugba. African oil bean seeds were purchased from dealers in a local market in Nsukka, Enugu State. Ugba was prepared in the laboratory using the traditional method [1]. The seeds were first boiled for 6$8 \mathrm{hrs}$ to soften the coat and enhance peeling. The cotyledons were then sliced longitudinally into $4.5 \mathrm{~cm} \times 0.1-0.2 \mathrm{~cm}$ slices, washed and boiled in water for 1-2 hrs, and drained and soaked in water for 10-12 hrs. After soaking, the slices were washed in several changes of water to reduce bitterness and allowed to drain in a basket. The slices were then wrapped in clean dry banana leaves (Musa sapientum Linn.) in 40$50 \mathrm{~g}$ wraps. The wraps were allowed to ferment for 3 days at room temperature $\left(28 \pm 2^{\circ} \mathrm{C}\right)$ to produce Ugba. Traditional fermentation was implemented in triplicate.

2.2. Pure Culture Production of Ugba. Ugba was produced in the laboratory according to the method described by Obeta [1]. One kilogram $(1 \mathrm{~kg})$ of African oil bean seeds was boiled dehulled, peeled, washed, and sliced for the traditional process. The slices were further washed and $20 \mathrm{~g}$ portions were placed into conical flasks and capped tightly with cotton wool and aluminium foil. The flasks containing the slices were sterilized by autoclaving at $110^{\circ} \mathrm{C}$ for 10 mins. Triplicate flasks were set up for pure culture process.

2.3. Development of Pure Isolates as Starters. Pure cultures of $B$. subtilis and B. megaterium isolated from the traditional process and identified by standard microbiological procedures were inoculated independently in $20 \mathrm{~mL}$ sterile $0.1 \%$ peptone water and incubated for $24 \mathrm{hrs}$. After incubation, the cultures were centrifuged and the culture pellets were washed repeatedly with sterile saline and distilled water. $0.1 \mathrm{~mL}$ of the cells were emulsified in $9.9 \mathrm{~mL}$ distilled water and pour plate method was used to ascertain the population of the cells and to check for culture purity.

2.4. Pure Culture Fermentation. Each flask was separately, aseptically inoculated with $1 \mathrm{~mL}$ suspension $\left(5.0 \times 10^{9} \mathrm{~mL}^{-1}\right)$ of $B$. subtilis or B. megaterium individually using a sterile pipette and mixed with the sample by simple manual mixing. Fermentation was allowed to proceed for $72 \mathrm{hrs}$ at room temperature with occasional manual mixing by shaking the flask. To check for purity of the process during the period of fermentation, $1 \mathrm{~g}$ of the fermenting slices was removed at 24-hour interval and at the end of fermentation and agitated in $9 \mathrm{~mL} 0.1 \%$ sterile peptone water. Smear of the sample was streaked on nutrient agar plate for isolation of the particular organism acting as a single pure culture. Triplicate pure culture flasks were homogenised and sampled for analysis of volatile compounds. Only pure culture processes were analysed for volatile compounds.

2.5. Analysis for Volatile Flavour Compounds: Sampling and Extraction Procedure. Samples for analysis were collected from naturally fermented Ugba and also from Ugba fermented with pure cultures of $B$. subtilis and B. megaterium. Samples were collected at 12-hour intervals for 3 days. One gram $(1 \mathrm{~g})$ of the fermenting sample was ground and homogenized in $9 \mathrm{~mL}$ diethyl ether to extract volatile flavour compounds. Whatman No. 1 filter paper was used to separate the mixture; then Millipore Filtration using membrane filter of $0.45 \mu \mathrm{m}$ pore size was used to remove particulate matter from the resulting filtrate. The resulting filtrate was placed in small ampoules, sealed, and stored at $-30^{\circ} \mathrm{C}$ until being required for analysis.

2.6. GC-MS Analysis. Analyses were done on GC-MS (QP 2010 plus; Shimadzu Corp, Japan) operated in electronimpact (EI) mode with an ionization voltage of $70 \mathrm{eV}$. Sample aliquot of $1 \mu \mathrm{L}$ was injected and analyses were done with split injection mode. The GC column oven temperature was $60^{\circ} \mathrm{C}$ and injector temperature was $250^{\circ} \mathrm{C}$ with $53.2 \mathrm{~mL} / \mathrm{min}$ flow and interface temperature of $250^{\circ} \mathrm{C}$. Helium at $56.2 \mathrm{kPa}$ was employed as the carrier gas. Oven temperature was held at $60^{\circ} \mathrm{C}$ for $2 \mathrm{mins}$, ramped to $180^{\circ} \mathrm{C}$ and held for $3 \mathrm{mins}$, and finally programmed at $280^{\circ} \mathrm{C}$ and held for 5 mins. The ion source temperature was $200^{\circ} \mathrm{C}$ and the solvent cut time was 2.50 mins. GC chromatograms of the fermenting African oil bean seeds were examined and each peak identified was confirmed by direct comparison of their chromatographic retention times, retention indices, and mass spectra with those of the authentic compounds and/or data in the NIST05 Mass Spectral Library.

\section{Results}

3.1. Traditional Production of Ugba. At the end of the traditional fermentation, the produced Ugba had a very light brown colour and exhibited classical aroma of the product, with a light, but sharp, ammoniacal smell. There was no visible sign of any slime on the slices which remained firm but slightly softer than the control/starting material. The product tasted like the traditional market samples with a slight distant bitter tinge. A total of 36 aroma compounds made up of 12 hydrocarbons, 10 esters, 5 alcohols, 2 phenols, 2 ketones, and one of each of furan, amine, acid, thiophene, and lactone were identified at different fermentation periods during natural fermentation (Table 1). 


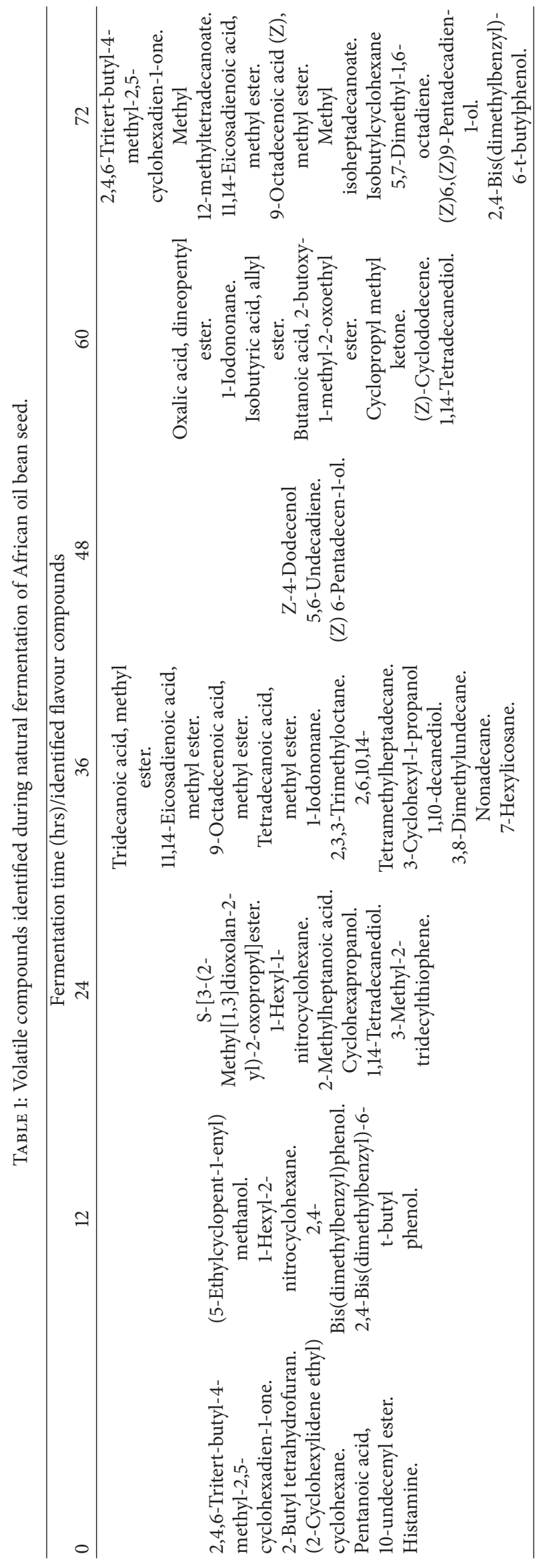


3.2. Pure Culture Production of Ugba. At the end of the pure culture process, the products of fermentation with two organisms were generally similar in colour, both being very light brown with no visible slime on the slices. The product of the $B$. subtilis fermentation, however, had only a slightly deeper ammoniacal smell than that of $B$. megaterium. Both products tasted similar to the product of natural process but were slightly bitterer than the natural process. Similarly, the product of $B$. megaterium was bitterer than that made with B. subtilis. The extract of oil seed fermented with B. subtilis yielded 30 aroma compounds comprising 10 hydrocarbons, 8 esters, 3 alcohols, 2 sulfur compounds, 2 amines, and one of each of acid, aldehyde, phenol, ketone, and furan (Table 2). On the other hand, sample fermented with $B$. megaterium produced 29 aroma compounds consisting of 9 hydrocarbons, 10 esters, 2 nitrogenous compounds, 2 ketones, 3 alcohols, and one of each of lactone, aldehyde, furan, and amine (Table 3).

\section{Discussion}

Volatile compounds have been shown to be partly responsible for the aroma of several fermented foods [7-11]. They are probably important players in the flavour of Ugba, as they have been shown to be important in a variety of Bacillus spp. fermented foods [2]. Ugba flavours are formed during fermentation as a result of breakdown of plant compounds as well as formation of microbial metabolites by the active populations responsible for the fermentation process. The ammoniacal flavour observed in Ugba is believed to result from the alkaline degradation of protein component of the seed by the fermenting Bacillus spp. [7]. Many of the aroma compounds identified in this study derived from the breakdown of lipids (fatty acid), proteins (amino acid), and other bioavailable compounds in Ugba through the activities of the microbial enzymes. Hydrocarbons, esters, alcohols, phenols, ketones, furan, and amines were detected in all the samples examined and the consistency of these various volatiles would suggest roles for them in the final flavour of the product, although minor. However, neither the flavour thresholds of these compounds in this product nor their precise individual contributions are yet known.

Hydrocarbons are assumed to be formed from fatty acid by lipoxygenase catalysis [12]. This may explain their abundance as volatile compounds in the fermented African oil bean seeds, since the seeds are rich in oil [13]. Nakamura et al. [14] suggested that hydrocarbons do not play a significant role as flavour compounds in roasted sesame since they possess a relatively weak aroma. If this be the case in Ugba, then the principal flavour compounds may be other compounds coproduced in the fermentation process. It is to be expected, as with all complex products, that the final flavour of Ugba will derive from the interaction of a variety of compounds.

Methyl esters of fatty acids are one of the largest group of volatile aroma compounds produced during the fermentation in both mixed culture natural fermentation and pure culture processes. These were largely produced during $36-48 \mathrm{hr}$ of fermentation and persisted in various forms to the end of the process. They are produced enzymatically during fermentation by the methanolysis of acyl-COA that is formed during fatty acid synthesis or degradation. These compounds have been reported to be responsible for quality sensory properties of various fermented foods [15]. 9-Octadecenoic acid, methyl ester; pentanoic acid, methyl ester; 11,14-eicosadienoic acid, methyl ester; and methyl 12-methyl tetradecanoate are methyl esters of fatty acids which occurred commonly and in significant amounts (from the peak areas) in all the samples.

Unfermented $(0 \mathrm{hr})$ samples contained 2-butyltetrahydrofuran which rapidly disappeared as fermentation progressed. Furanic compounds are among the aroma compounds obtained from carbohydrate degradation [16]. This is consistent with the report of high carbohydrate content of unfermented Pentaclethra macrophylla [17]. Histamine was identified at $0 \mathrm{hr}$ fermentation and cyclopentanamine was identified in the sample fermented with $B$. subtilis at $36 \mathrm{hr}$. The presence of these compounds may be attributed to the enzymatic decarboxylation of amino acid in the seeds during fermentation. The presence of nitrogenous compounds, butyl isocyanide and acetonitrile, in the sample fermented with $B$. megaterium at $12 \mathrm{hr}$ and $48 \mathrm{hr}$, is indicative of deaminase activity during the fermentation. Unfermented Ugba has been reported to contain cyanide and other toxic compounds/antimetabolites [18] as has been reported in a variety of oil seeds [19]. Some volatile sulfur compounds in food are obtained by a variety of enzymatic reactions and/or as products of secondary metabolism of leucine and cysteine [12]. Methane sulfonic anhydride and t-butyl sulfinate, Omethyl, were present at $12 \mathrm{hr}$ and $60 \mathrm{hr}$, respectively, in the sample fermented with $B$. subtilis.

Considerable amounts of various alcohols were identified during the fermentation in all samples. Of these, 1,14tetradecanediol and 1,10-decanediol occurred severally at different periods of fermentation in all the samples. 3,7Dimethyl-7-octen-1-ol was identified in the sample fermented with B. megaterium. Many alcohols have been described as possessing undesirable odor which partially contributes to "raw" or "beany" flavour of soya bean [20]. A small number of aldehydes, ketones, and acids were identified in this study. Fatty acids and amino acids are precursor of a great number of volatile aldehydes [12]. It is conceivable that these compounds contribute to the final flavour of fermented African oil bean seeds. Aldehyde can also be obtained as metabolic by-products of the enzymatic transamination or oxidative deamination of amino acid. 2,4-Hexadienal and 14-heptadecenal are aldehydes identified in the samples fermented with B. subtilis and B. megaterium at $60 \mathrm{hr}$ of fermentation. However, they did not persist nor were they present in the natural process. Although B. subtilis and $B$. megaterium are present in natural fermentation process the profile of volatiles differed between pure culture and traditional one. This is understandable, as the mixture of other microorganisms present in the natural process may modulate the variety, quantity, and persistence of different volatile compounds.

Phenolic compounds when present in fermented foods impart smoky and/brown odour [14]. Phenol, 2,4-bis(dimethylbenzyl) phenol, and 2,4-bis(dimethylbenzyl)-6-t-butylphenol identified during natural fermentation were not 


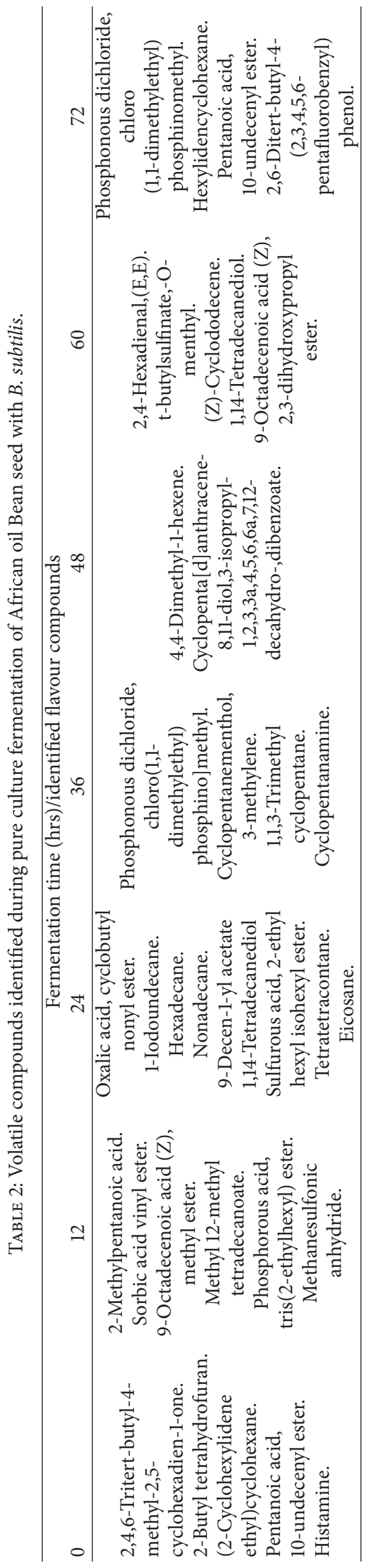




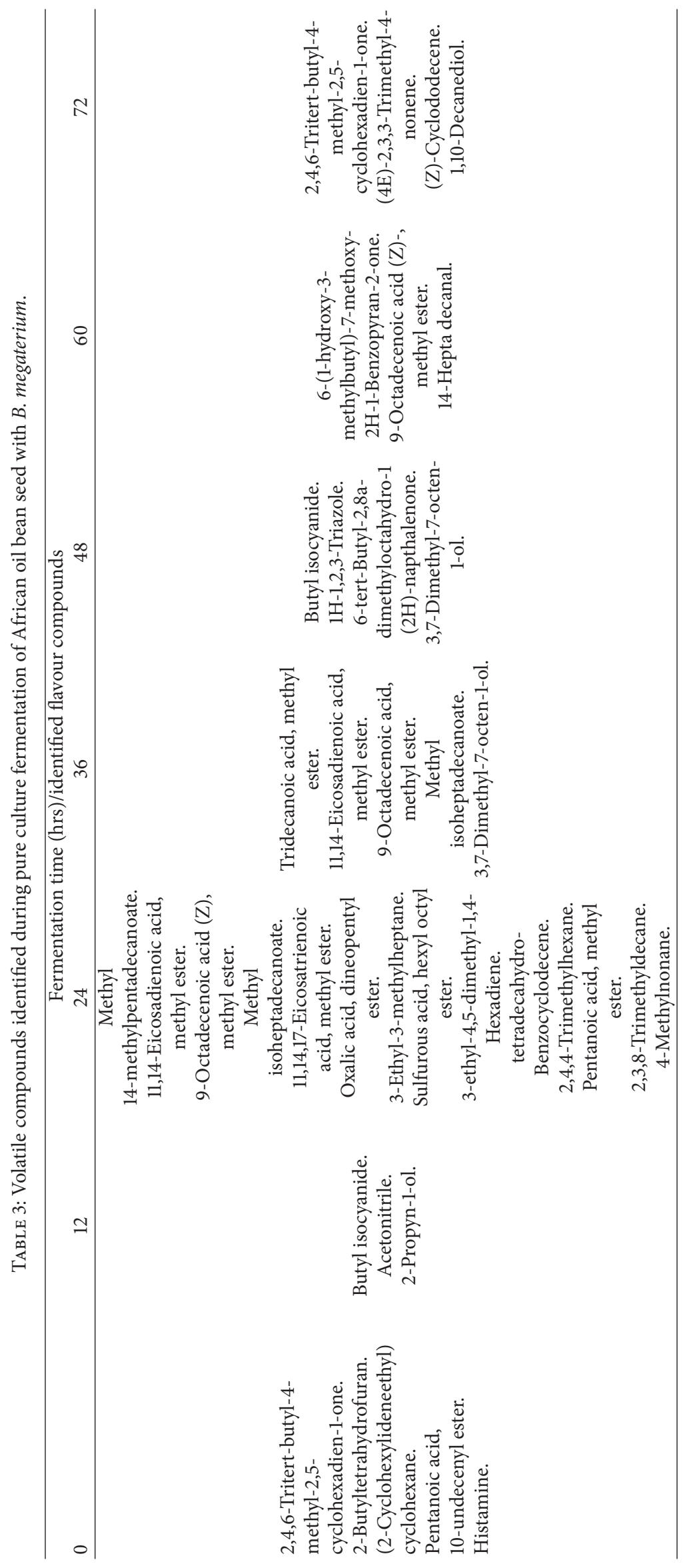


detected in pure culture fermentation and may be attributed to the smoked banana leaves used in wrapping the slices prior to fermentation. Although relatively small amounts of aldehyde, ketone, furans, amines, lactones acids, and thiophenes were identified in this study, they are expected to play important roles in the aroma of Ugba because of their low detection/aroma thresholds as has been reported in roasted chicory [21], in the dry scented Thai flowers used in tea production [22] and in roasted Malaysian almond nuts [23].

\section{Conclusion}

A vast array of volatile compounds has been identified in fermented Pentaclethra macrophylla seeds (Ugba). The variety and quantity of these volatiles change with the time of fermentation and the participating populations. The dynamic nature of evolution of volatile compounds is interesting for modulating the flavour of the final product. It remains to be demonstrated, the relative amounts, flavour thresholds, and specific contribution of the various compounds to the final flavour of the ready to eat fermented seeds. Clearly, a proper understanding of the roles of the various flavour compounds will assist in the modulation of Ugba flavour for the various possible uses of this important fermented seasoning and for a possible use in food processing industries and homes as a seasoning.

\section{Conflict of Interests}

The authors declare that there is no conflict of interests regarding the publication of this paper.

\section{References}

[1] J. A. N. Obeta, "A note on the micro-organisms associated with the fermentation of seeds of the African oil bean tree (Pentaclethra macrophylla)," Journal of Applied Bacteriology, vol. 54, no. 3, pp. 433-435, 1983.

[2] M. Beaumont, "Flavouring composition prepared by fermentation with Bacillus spp," International Journal of Food Microbiology, vol. 75, no. 3, pp. 189-196, 2002.

[3] H. O. Njoku and C. P. Okemadu, "Biochemical changes during the natural fermentation of the African oilbean (Pentaclethra macrophylla) for the production of ugba," Journal of the Science of Food and Agriculture, vol. 49, no. 4, pp. 457-465, 1989.

[4] H. O. Njoku, J. N. Ogbulie, and C. Nnubia, "Microbiological study of the traditional processing of African oil bean (Pentaclethra macrophylla Bentham) for Ugba production," Food Microbiology, vol. 7, no. 1, pp. 13-26, 1990.

[5] N. R. Isu and C. O. Ofuya, "Improvement of the traditional processing and fermentation of African oil bean (Pentaclethra macrophyllaBentham) into a food snack-'Ugba"' International Journal of Food Microbiology, vol. 59, no. 3, pp. 235-239, 2000.

[6] I. Ahaotu, A. Anyogu, O. H. Njoku, N. N. Odu, J. P. Sutherland, and L. I. I. Ouoba, "Molecular identification and safety of Bacillus species involved in the fermentation of African oil beans (Pentaclethra macrophylla Benth) for production of Ugba," International Journal of Food Microbiology, vol. 162, no. 1, pp. 95-104, 2013.
[7] C. C. Ogueke, J. N. Nwosu, C. I. Owuamanam, and J. N. Iwouno, "Ugba, the fermented African Oilbean Seeds; its production, chemical composition, preservation, safety and health benefits," Pakistan Journal of Biological Sciences, vol. 13, no. 10, pp. 489496, 2010.

[8] N. O. Kabuo, J. O. Uzuegbu, C. N. Ubbaonu, and E. U. Onyeka, "Effect of chemical compounds produced by microorganisms on organoleptic properties of ugba (Pentaclethra macrophylla Benth) during fermentation," in Proceedings of the Annual Conference of Nigerian Institute of Food Science and Technology, pp. 175-176, Abuja, Nigeria, October 2007.

[9] S.-J. Lee and B. Ahn, "Comparison of volatile components in fermented soybean pastes using simultaneous distillation and extraction (SDE) with sensory characterisation," Food Chemistry, vol. 114, no. 2, pp. 600-609, 2009.

[10] J. Zhao, X. Dai, X. Liu, H. Zhang, J. Tang, and W. Chen, "Comparison of aroma compounds in naturally fermented and inoculated Chinese soybean pastes by GC-MS and GCOlfactometry analysis," Food Control, vol. 22, no. 6, pp. 10081013, 2011.

[11] H. Jeleń, M. Majcher, A. Ginja, and M. Kuligowski, "Determination of compounds responsible for tempeh aroma," Food Chemistry, vol. 141, no. 1, pp. 459-465, 2013.

[12] H.-D. Belitz, W. Grosch, and P. Schieberle, "Aroma compounds," in Food Chemistry, pp. 340-400, Springer, Berlin, Germany, 4th edition, 2009.

[13] F. R. Irvine, Woody Plants of Ghana, Oxford University Press, London, UK, 1961.

[14] S. Nakamura, O. Nishmura, H. Masuda, and S. Mihara, "Identification of volatile flavour components of the oil from roasted sesame," Agricultural and Biological Chemistry, vol. 53, pp. 18911899, 1989.

[15] R. Perestrelo, A. Fernandes, F. F. Albuquerque, J. C. Marques, and J. S. Câmara, "Analytical characterization of the aroma of Tinta Negra Mole red wine: identification of the main odorants compounds," Analytica Chimica Acta, vol. 563, no. 1-2, pp. 154$164,2006$.

[16] G. Morini and J. A. Maga, "Volatile compounds in roasted and boiled Chinese chestnuts (Castanea molissima)," LWT_Food Science and Technology, vol. 28, no. 6, pp. 638-640, 1995.

[17] S. C. Achinewhu, "The effect of fermentation on carbohydrate and fatty acid composition of African oil bean seed (Pentaclethra macrophylla)," Food Chemistry, vol. 19, no. 2, pp. 105-116, 1986.

[18] M. O. Isichei and S. C. Achinewhu, "The nutritive value of African oil bean seeds (itPentaclethra macrophylla)," Food Chemistry, vol. 30, no. 2, pp. 83-92, 1988.

[19] J. P. Walradt, A. O. Pittet, T. E. Kinlin, R. Muralidhara, and A. Sanderson, "Volatile compounds in roasted peanut," Journal of Agriculture and Food Chemistry, vol. 19, p. 972, 1971.

[20] W. F. Wilkens and F. M. Lin, "Volatile flavor components of deep fat-fried soybeans," Journal of Agricultural and Food Chemistry, vol. 18, no. 3, pp. 337-339, 1970.

[21] H. H. Baek and K. R. Cadwallader, "Roasted chicory aroma evaluation by gas chromatography/mass spectrometry/olfactometry," Journal of Food Science, vol. 63, no. 2, pp. 234-237, 1998.

[22] R. Samakradhamrongthai, N. Utama-Ang, and P. Thakeow, "Identification of volatile compounds released from dry scented Thai flowers and their potential application in flower-mixed tea," Asian Journal of Food and Agro-Indusry, vol. 2, pp. 525-534, 2009. 
[23] O. Lasekan and K. Abbas, "Analysis of volatile flavour compounds and acrylamide in roasted Malaysian tropical almond (Terminalia catappa) nuts using supercritical fluid extraction," Food and Chemical Toxicology, vol. 48, no. 8-9, pp. 2212-2216, 2010. 

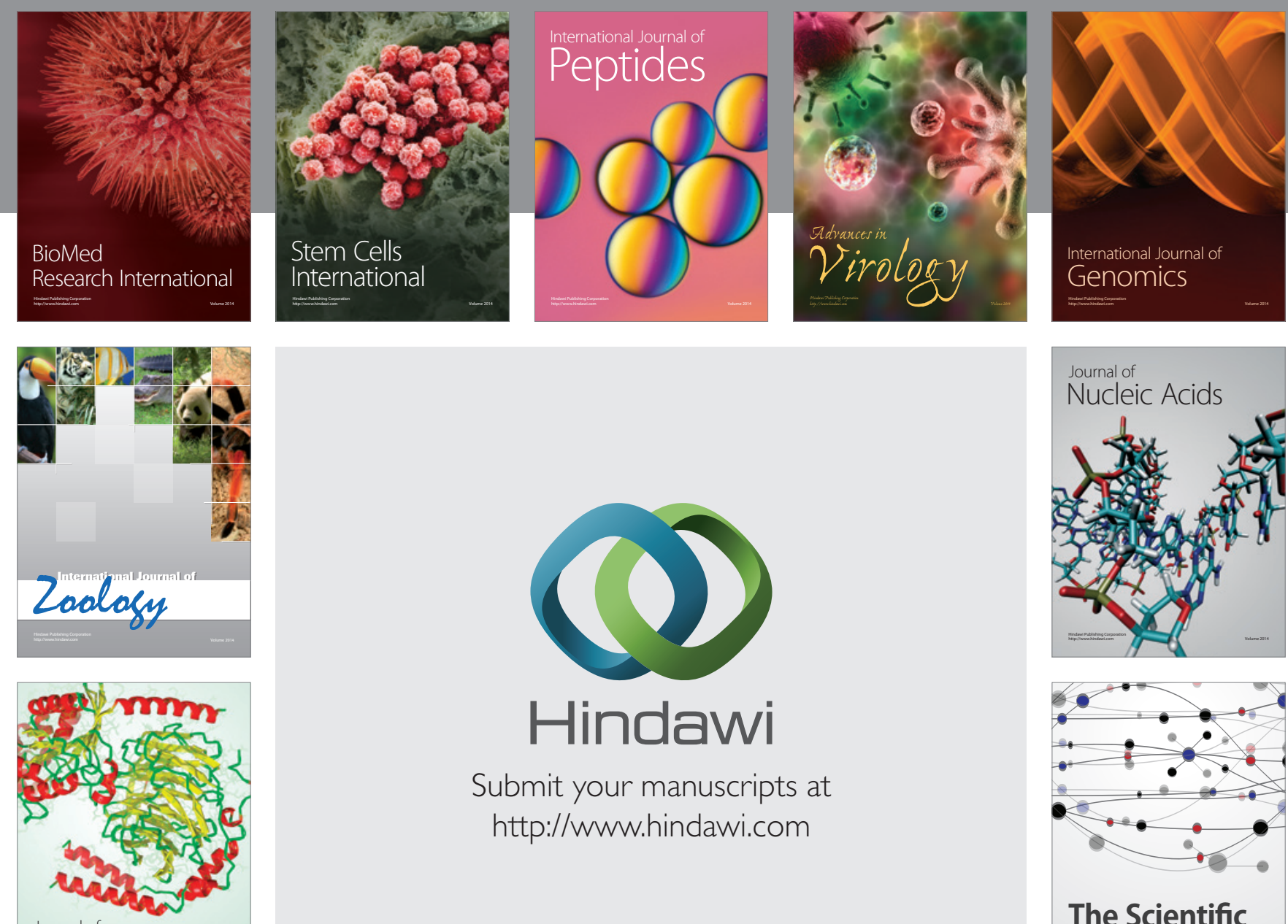

Submit your manuscripts at

http://www.hindawi.com

Journal of
Signal Transduction
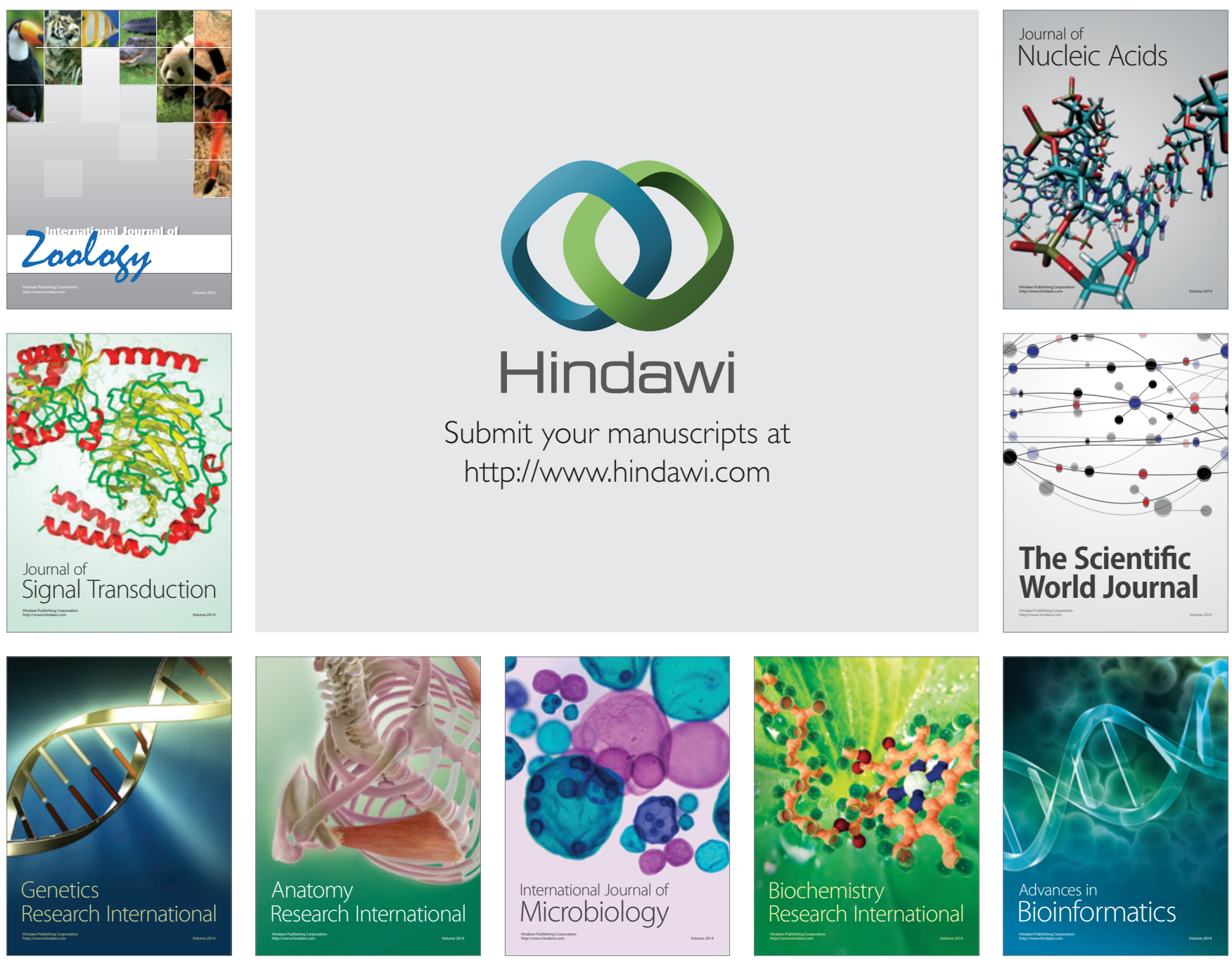

The Scientific World Journal
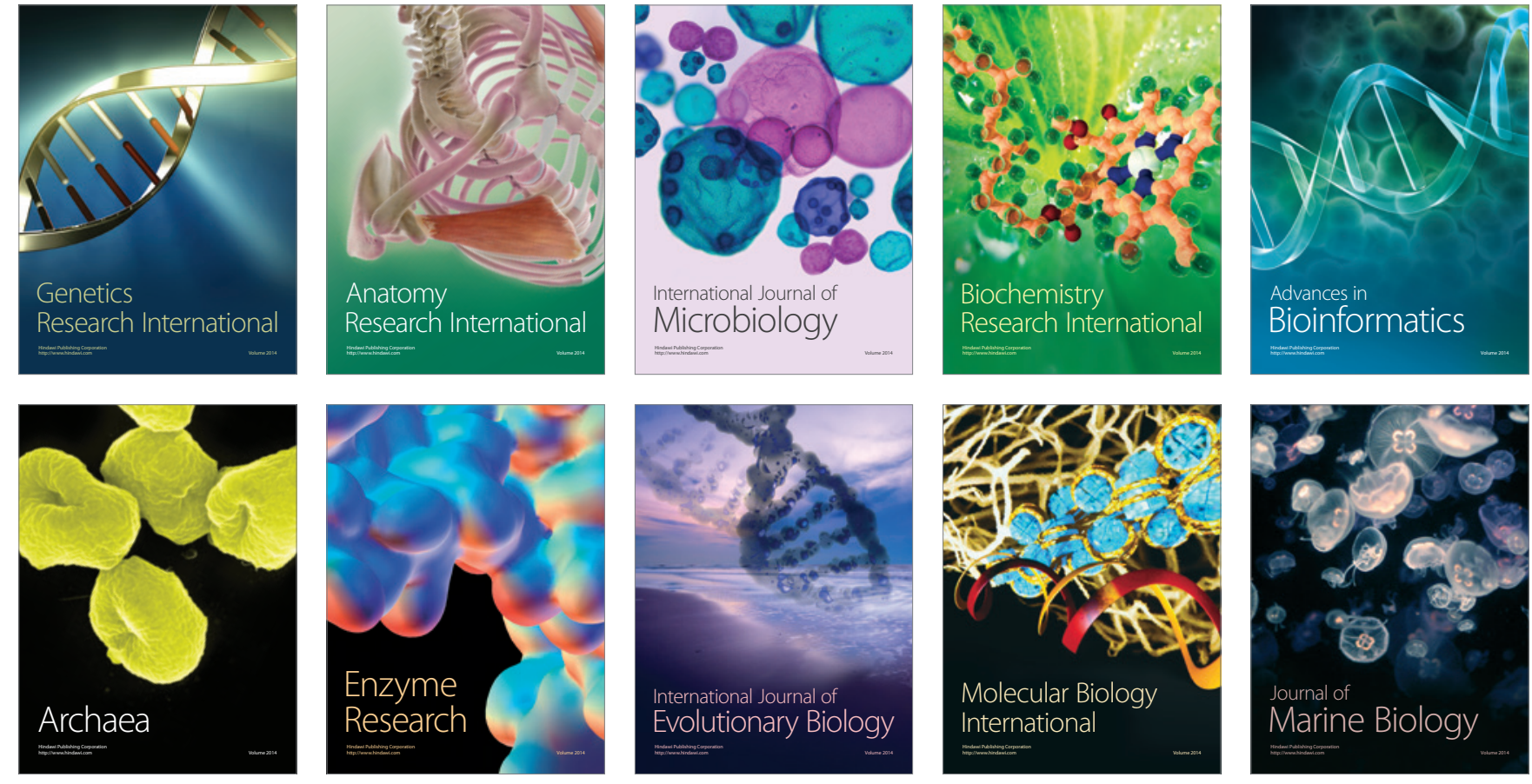